Article

\title{
Developing the Transformative Capacity of Social Innovation through Learning: A Conceptual Framework and Research Agenda for the Roles of Network Leadership
}

\author{
Tim Strasser ${ }^{1, *}$, Joop de Kraker ${ }^{1,2}$ and René Kemp ${ }^{1,3}$ \\ 1 International Center for Integrated Assessment and Sustainable Development, Maastricht University, \\ 6211 KR Maastricht, The Netherlands; j.dekraker@maastrichtuniversity.nl or joop.dekraker@ou.nl (J.d.K.); \\ r.kemp@maastrichtuniversity.nl (R.K.) \\ 2 Faculty of Management, Science \& Technology, Open University, 6419 AT Heerlen, The Netherlands \\ 3 United Nations University-Maastricht Economic and Social Research Institute on Innovation and \\ Technology (UNU-MERIT), United Nations University, 6211 AX Maastricht, The Netherlands \\ * Correspondence: tim.strasser@maastrichtuniversity.nl; Tel.: +31-684-817-636
}

Received: 30 September 2018; Accepted: 18 February 2019; Published: 1 March 2019

\begin{abstract}
Learning processes play a crucial role in the development of the transformative capacity of social innovation actors. This article builds on the recently developed Transformative Social Innovation (TSI) theory to propose a conceptual framework and research agenda for understanding and investigating the roles and limits of network leadership in supporting learning processes that serve to develop the transformative capacity of social innovation. This focus on network leadership is underdeveloped so far in TSI theory. Addressing this research gap also serves to increase the practical relevance of TSI theory to practitioners engaged in network leadership. After presenting a synopsis of TSI theory, we present an overview of the elements of the conceptual framework, which are successively specified throughout the article. First, transformative change is conceptualized, involving three institutional dimensions: depth, width and length. Based on this, a definition of transformative capacity is proposed that addresses change across these three dimensions. We then describe how various types of learning processes can contribute to the development of transformative capacity. Next, we outline the roles of network leadership in supporting these learning processes across various network levels. We conclude with a research agenda for empirically investigating these roles of network leaders as agents for advancing transformative changes for sustainability.
\end{abstract}

Keywords: transformative social innovation; learning; networks; network leadership

\section{Introduction}

Interest in social innovation has become loaded with many hopes and assumptions about the potential of social innovation to address urgent and complex sustainability challenges [1]. Of particular relevance here is the recognition that these challenges call for transformative responses that go beyond superficial adaptations of existing institutions [2]; that is, a more fundamental redesign of socio-economic, cultural, educational and political institutions is called for. The relation between social innovation and transformative change is therefore of particular interest. This relation has recently been studied by the EU-funded TRANSIT project, producing a theory of transformative social innovation (TSI theory). This empirically grounded theory particularly emphasizes processes of collective experimentation and learning in social innovation initiatives and networks as a foundational element of contributing to transformative changes [1]. 
However, very little research exists on the role of learning in the context of transformative social innovation [3], and current TSI theory only offers some starting points for understanding transformative capacity [4] as a result of learning processes. Secondly, the role of networks as a mechanism for supporting those learning processes, deserves much more in-depth understanding $[5,6]$, in particular, the aspect of network leadership: how various actors in social innovation networks can purposefully shape and support learning processes to strengthen transformative capacity $[7,8]$. This would significantly enhance the practical value of TSI theory to social innovation practitioners engaging in network leadership.

The purpose of this article is to present a conceptual framework and research agenda for guiding further research that can address these shortcomings in the current state of TSI theory [9] and to enhance its practical relevance (it was one of the central ambitions of the TRANSIT project to develop a theory that is relevant for practice; however, much more can be done in this regard). This article responds specifically to two suggestions made by TRANSIT researchers for further research:

(1) "Further development of the theoretical and conceptual framework for TSI. Especially, making our 'institutional framework' for TSI more readily analytically tractable, with the aim to both facilitate the further development of middle-range theory, but also to craft a conceptual language around institutional change which is recognizable and useful in policy and practice" [1] (p. 169).

(2) "Much remains to be tested and explored regarding the development of heuristics for the 'empowerment' of SI initiatives. Throughout the many cases studied in this research, the members of SI initiatives often expressed a need for better 'theories of change' to inform their strategies" [4] (p. 20).

We respond to these suggestions by proposing a conceptual framework of how learning processes can strengthen the capacity to contribute to transformative change, across three dimensions of institutions, and how network leadership can shape those learning processes. So far TSI theory has mostly been focused on describing the complex, multi-dimensional dynamics of TSI processes, stopping short of identifying chains of causality and heuristics for agency [4]. Through further testing and refinement of this framework in empirical cases, a practice-relevant theory of change can be developed. This will fill an important gap in existing TSI theory and make a contribution to the wider literature on transition studies, social innovation, social learning, and network leadership.

As this article aims to further develop TSI theory, ample references are made to TRANSIT project reports, including the final theory deliverable [1], as well as the deliverable on social learning [3]. The resulting framework is based on literature and empirical findings from the TRANSIT project, as well as literature on social learning and network leadership. Empirical examples are used to illustrate the conceptual framework, drawing on some of the cases studied in the TRANSIT project (see Appendix A for an overview). The framework is still largely hypothetical at this stage and further empirical work needs to be conducted to test and refine it.

The article is structured as follows: Section 2 highlights key aspects of TSI theory and outlines the elements to be further developed. Section 3 articulates three dimensions of institutions to assess transformative change, which form the basis for consequently defining transformative capacity in Section 4. Section 5 outlines the types of learning processes that can serve to strengthen this transformative capacity. Section 6 then addresses the roles of network leadership in shaping and supporting those learning processes. The discussion and conclusion finally offers a comprehensive overview of the conceptual framework and presents a research agenda for further testing and refining this framework empirically.

\section{Transformative Social Innovation Theory}

Transformative social innovation (TSI) theory was developed in the TRANSIT project (TRANsformative Social Innovation Theory) for the European Commission during the period of January 2014-December 2017. It investigated 20 transnational networks and over 100 local SI initiatives 
across 27 countries that are active on a large variety of issues. Empirically grounded theoretical propositions were developed regarding the relationship between social innovation and transformative change and how the SI actors can become (dis)empowered in their efforts. As the TSI theory is quite vast and nuanced, it would be beyond the scope of this article to go much more into detail here (see Appendix B for an overview of the main aspects). The following thus merely provides a short explanation of the core concepts of social innovation, transformative change and the process of institutionalisation, as a basis for further developing TSI theory in the following sections.

Social innovation (SI) is defined in TSI theory as new social relations, involving new ways of doing, organizing, framing and knowing (DOFK) [1,10]. It is understood both as a process of changing social relations and as a qualitative property of ideas, objects and activities and/or (groups of) people [1] (p. 14). The key difference from technical innovation is that the focus is not on new technologies or material infrastructures but the social relations between people (producers and consumers, citizens and government, refugees and native inhabitants, etc.) as well as between people and any other aspect in society (people and nature, producers and their products, etc.).

Social innovation initiatives studied in the TRANSIT project (see Appendix A for a short overview of the cases and Jørgensen et al. [11], for a more elaborate overview) include community-based initiatives like Transition Towns and Ecovillages, social enterprise-oriented initiatives like Impact Hubs and Ashoka, education-focused initiatives like Design for Social Innovation and Sustainability (DESIS) and the Living Knowledge Network, peer-to-peer production initiatives like Hackerspaces and Fablabs, or policy-oriented initiatives like basic income and participatory budgeting. These promote more socially and environmentally responsible, ethical, solidarity and collaboration-based models of the economy, banking, agriculture, material production, design, education and community life. For instance, the relational changes involve, interpersonal relations based on trust rather than status, market relations based on purpose rather than profit, and productive relations based on co-ownership and collaboration rather than hierarchy and competition. These relations involve new DOFK in terms of doings such as producing community-owned energy; new ways of organizing collective action such as sociocratic decision-making; new framings such as envisioning the purpose of business as solving social problems; and new ways of knowing such as the combination of traditional knowledge with modern science. New social relations can also involve doing old things in new ways, reinvigorating old ways of DOFK that have been forgotten or marginalized, or combining them in new ways with other aspects of the sociomaterial context (e.g., unconditional basic income is an idea that is over a hundred years old but resurfaced in recent decades in response to the economic crisis and changes in welfare systems). The core concern of TSI theory is how these social innovations can contribute to transformative change.

According to TSI theory, transformative change is a "change that challenges, alters and / or replaces dominant institutions in a specific sociomaterial context" [1] (p. 17). Institutions involve both formal and informal institutions [12], defined as: "norms, rules, conventions and values [13] (p. 46) that both constrain and enable social relations and established patterns of doing, organising, framing and knowing" [1] (p. 15). Formal institutions refer to more tangible phenomena like policies, incentive structures, or customs like marriage, private property, educational institutions, welfare systems, and free trade regulations. Informal institutions involve less tangible cultural attitudes, beliefs, norms or shared values like individualism, hierarchy or beliefs about the purpose of the economy. While transformative change involves institutional change, not all institutional change is transformative. In TSI theory, the unique characteristic of transformative change, as opposed to non-transformative change, is that it involves challenging, altering or replacing dominant institutions.

Normative and directional diversity is an integral feature of transformative social innovation. Many different initiatives strive for diverse institutional changes and pursue very different strategies. Overall, topics of a more sustainable, just and humane economy are recurring to various degrees in most initiatives studied, and many TSI initiatives challenge the dominant institutions of neoliberal economic development [14]. For example: Transition Towns aim to transform global capital-oriented 
and individualistic urban economies by working towards re-localised community-based economies; Impact Hubs and Ashoka aim to transform profit and competition-based business models by promoting social entrepreneurship as a way of combining working for social causes with earning an income; while Time Banks aim to transform exclusionary value-exchange and welfare provisioning systems by working towards complementary currency systems that foster community cohesion and empowerment of marginalized individuals.

Dominant institutions are difficult to transform, as they are often strongly established as taken-for-granted, or "normal" for a large part of society (even if not everyone agrees with them) and are embedded in powerful mechanisms for reproducing them. "Dominant institutions can be viewed as the dominant ways of doing, organising, framing and knowing (DOFK), that have been established in the social-material context" [1] (p. 15). For example, the dominance of neoliberal economic development is related to the ways of framing economic growth as the primary policy objective, doing activities that increase profits, knowing about the success of those activities through indicators like profit margins or GDP, and organising service delivery through private ownership and markets more than state or civil society-based arrangements. These have become widely and firmly established, or institutionalised, in legal, cultural, physical and organisational structures and routines in recent decades.

To become transformative, social innovation thus involves a process of institutionalising changes in social relations and related DOFK, in a way that challenges, alters and/or replaces such dominant institutions. This institutionalisation process is defined as: "the process by which changes in institutional structures emerge and become more widely embedded" [1] (p. 17). Social innovation initiatives with transformative ambitions start out with an idea about what they want to change, a set of principles and values, as well as a narrative of change, or set of ideas about how to bring this change about. These initial ideas get further shaped over time, through direct experimentation, reflection on better ways to reach their goals and interactions with other (collaborative and antagonistic) actors and initiatives. However, the institutionalisation process is full of challenges and paradoxes, such as risks of capture, appropriation or marginalization by dominant institutions [15]. Radical ideas might diffuse in less radical ways when interacting with other dominant institutional logics, but such interactions are needed for fostering change in dominant institutions.

A central question for TSI theory and practice thus involves how to better understand and navigate this institutionalisation process [16], in order to assess and achieve transformative change, respectively. More specific properties of institutions need to be articulated to assess transformative change and thereby guide or evaluate attempts to transform dominant institutions. TRANSIT researchers suggested that institutions "exhibit varying degrees of 'depth' and 'stability"'. Yet, while they stated that "a conceptual language for describing such properties needs to be articulated in developing a theory of TSI" [1] (p. 16), such a conceptual language was not offered or operationalized. In the following section, we describe three institutional dimensions as a way of clarifying the key aspects of the institutionalisation process that need to be integrated for bringing about transformative institutional change. This forms the basis for the following sections on transformative capacity, learning processes and network leadership (see Figure 1 for an overview). 


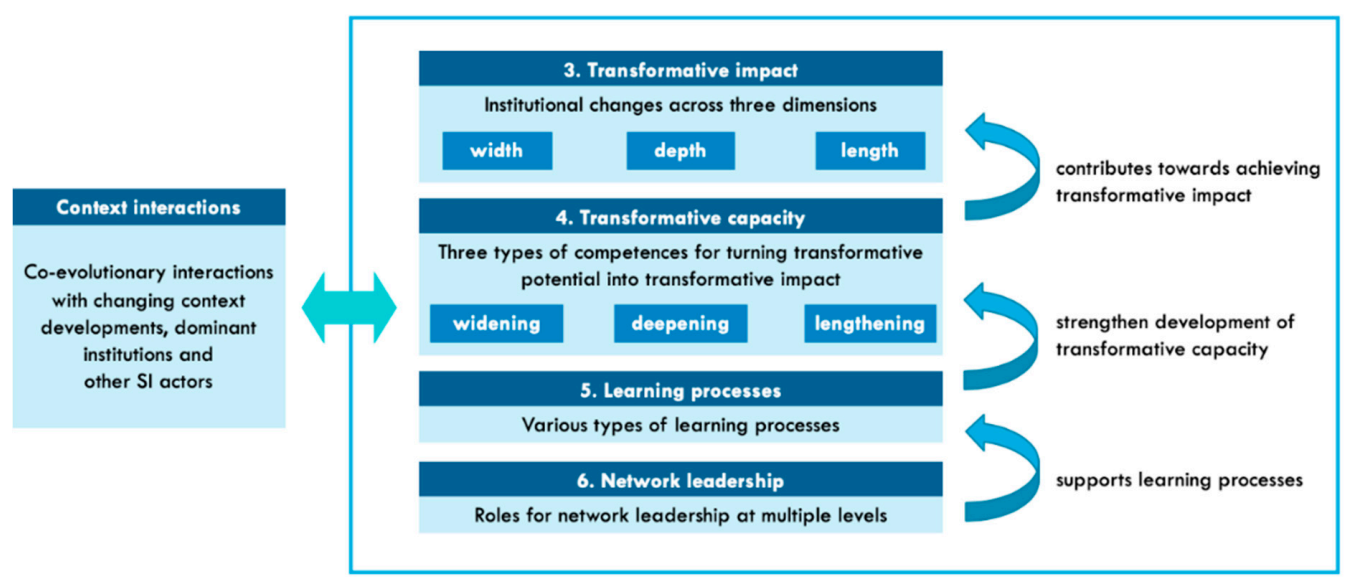

Figure 1. Overview of conceptual framework (numbers represent the following sections) with causal relations between network leadership, learning processes, transformative capacity and transformative impact, in interaction with the wider social context.

\section{Three Institutional Dimensions to Assess Transformative Impact}

This section builds on TSI theory to elaborate a more specific conceptualisation of transformative institutional change. Three dimensions of institutions are described here: depth, width and length (see Figure 2). These dimensions can be understood as scales, or "degrees of institutionalisation" [1] (p. 18). The three dimensions of institutions serve to describe more clearly what transformative change consists of: institutional change that challenges, alters and/or replaces dominant institutions in their depth, width and length dimensions. TSI processes can thus involve both the critique and re-construction [17,18] of dominant institutions and the cultivation of alternative institutions [19], in terms of weakening or strengthening their degrees of institutionalisation. Institutional change is known to involve complex dynamics, which are not explained in more detail here. See for instance Mahoney and Thelen [20] about how institutions may be replaced, adjusted, used differently or complemented by new ones, and in response to changing circumstances [21]. We suggest that the proposed three dimensions offer a perspective that is recognizable in practice and is helpful to be more specific about how to understand and assess the degrees of transformative impact of social innovations (defined further below).

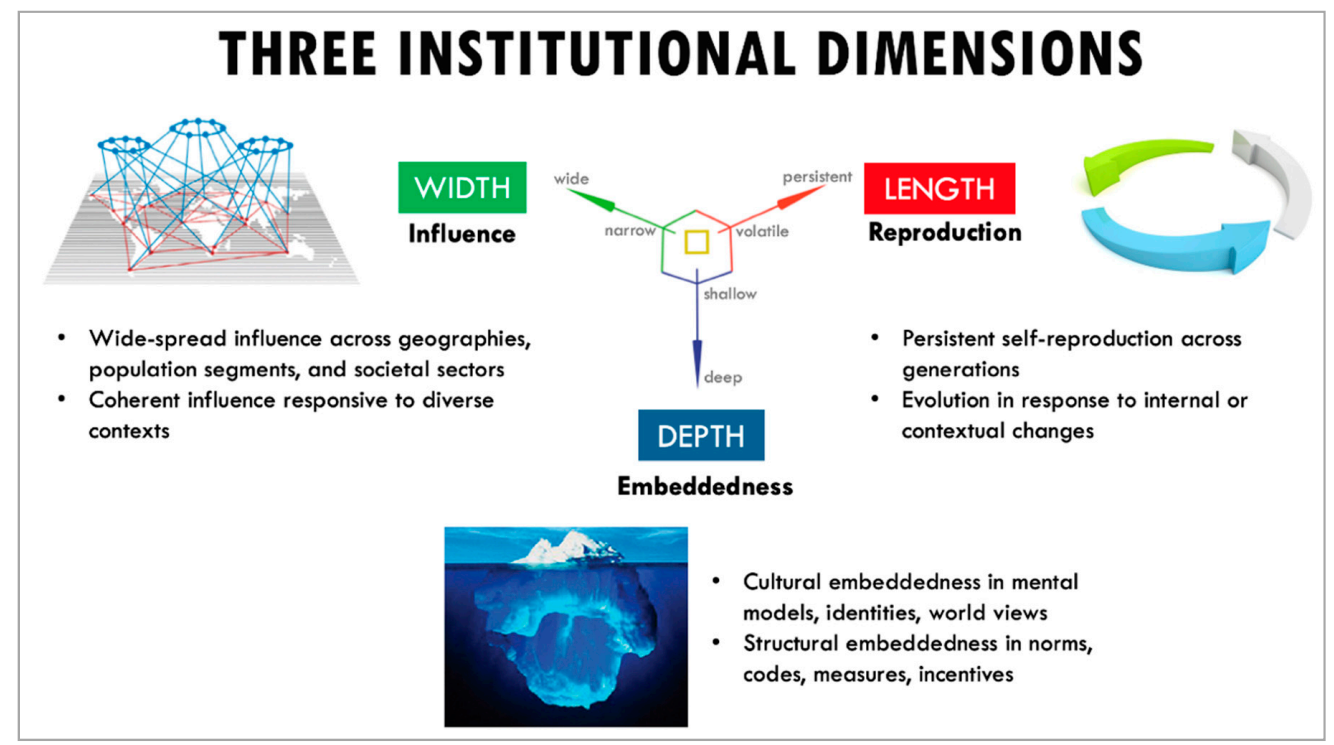

Figure 2. Overview of three institutional dimensions: width, depth and length, as scales or degrees of institutionalisation (narrow-wide; shallow-deep; volatile-persistent). 


\subsection{Depth: Cultural and Structural Embeddedness}

The depth dimension of institutions stands for how deeply their characteristics (DOFK) are culturally and structurally embedded, or "entrenched in the sense that it is costly to choose other practices, technologies, or rules" [22] (p. 282). This involves both the informal and formal aspects; that is, on the one hand, mental models, values, core assumptions, worldviews and identities and, on the other hand, policies, constitutions, or incentive mechanisms. A high degree of depth can make institutions very difficult to challenge or question: there might be a lack of awareness about their existence or influence, or there may be strong (self-)protection or regulation mechanisms around them, making it costly to change them or choose other institutions. More "shallow" institutions would be more readily consciously identified and less costly or more vulnerable to change.

\subsection{Width: Wide-Spread and Coherent Influence}

The width dimension of institutions represents how widely influential their characteristics (DOFK) are across geographical and cultural contexts, population segments, and societal sectors. Dominant institutions are very widely influential on (inter)national or even global scales, affecting millions of people from various ethnic, cultural, income-based (etc.) population segments, and across economic, public and civil domains. While there may be significant differences in how they are enacted in different contexts, dominant institutions maintain a high level of coherence, in the sense of adhering to core principles. More "narrow" institutions are rather particular to a certain region, segment of a population, or type of organisation or sectorial domain, or exhibit low degrees of coherence across those different contexts.

\subsection{Length: Persistent and Evolving Self-Reproduction}

The length dimension of institutions represents how persistently their characteristics (DOFK) are reproduced through self-generating mechanisms in highly resilient, yet adaptive ways over long spans of time [22] (p. 282). While persistence can involve some degree of staying recognizable as "the same" institution over time, it also constitutes dynamic evolution and adaptation in response to internal or contextual changes or challenges and incorporation of new perspectives or practices. Dominant institutions therefore have a high degree of continuity across the duration of system cycles (e.g., election periods), generations of organisational members or leaders, and even human lifetimes. More volatile institutions are more at risk of disintegration or becoming less influential, due to changes among people promoting or enacting them, or a failure to adapt to changing circumstances, leading to dissipation or replacement by other institutions.

The three dimensions are useful in assessing the degrees of institutionalisation of the core elements of TSI and, thereby, specify the varying degrees of transformative impacts in different places or contexts and at different points of time; that is, assessing how deeply embedded (depth), widely influential (width) and persistently reproduced (length) the institutional changes have become and to what extent they have challenged, altered and/or replaced dominant institutions in relation to these three dimensions. The transformative impact can thus be assessed in terms of the degree to which the core elements (DOFK) of the socially innovative relations have become:

- Deeply embedded in cultural and structural aspects of the socio-material context. For instance: principles of collaborative decision-making, trust-based interaction, regenerative design or holistic assessment having become embedded in mental models, identities, legislation and/or accountability mechanisms.

- Widely adopted and adapted by numerous and diverse groups of people, across geographic, organisational or sectorial contexts, as well as how coherent these adaptations are across contexts in terms of embodying similar underlying principles or patterns of relationships.

- Persistently reproduced and continuously developed, independent of the actors actively promoting the social innovation and across generations of roles and lifetimes. 
Achieving these three together is very difficult and rare. Often innovations spread wide but fail to change institutions more fundamentally, while being vulnerable to organizational discontinuity. Other innovations challenge institutions at a deep level but fail to establish this change more widely or beyond mere prototype experiments. The following section describes the required capacity of social innovations to achieve a transformative impact in all three dimensions.

\section{Transformative Capacity: Turning Potential into Impact}

In order for social innovations to become transformative, SI actors need to successfully navigate the institutionalisation process through which the transformative potential of a social innovation develops into transformative impact. This section describes what these terms mean and what type of competences SI actors need to have or develop in this respect.

The transformative potential of a social innovation refers to its "inherent and/or intended qualities to challenge, alter and/or replace dominant institutions in a specific context" [1] (p. 18). These "qualities" refer to the socially innovative relations, including the ways of doing, organizing, framing and knowing (DOFK) promoted by SI actors. In the case of basic income, the intention is to fundamentally alter the welfare system by replacing numerous welfare provisioning processes (based on need and eligibility) with an equal and unconditional monthly payment to all inhabitants of a certain area, which is sufficient to cover basic living costs. This has the potential to replace not just the ways of organizing welfare, but also the framings of what citizens are entitled to and the relations between workers, employers and the state. When such innovations are in a nascent stage of institutionalisation (i.e., narrow, shallow and volatile), they can be understood as "proto-institutions", or "institutions in the making" [22] (p. 283). Transformative potential can lead to a transformative impact if these proto-institutions successfully develop into more wide-spread, deeply entrenched and persistent institutions. Returning to the basic income example, this would mean that citizens of many countries would not only have the legal right to an unconditional basic income, but that this would be generally understood as normal, desirable and structurally secured to persist, independent of political elections.

Transformative capacity can then be understood as the ability to turn transformative potential into transformative impact. This is an attribute of the collective of SI actors, referring to the sum of competences that are needed among a distributed network of actors for shaping institutionalisation processes [4]. TSI theory views agency as distributed throughout a network of actors, rather than just an attribute of individual people or organisations [1,9]. While individuals can have considerable impacts in their local environments, they "tend to become key SI actors only by virtue of their embedding in and empowerment through various kinds of networks" [1] (p. 52). This includes not just the network of like-minded people from a particular SI network, but also other networks, organisations and incumbent actors who make up the wider "action field" [1,21]. For example, Transition Town initiatives are part of the wider urban development action field, including urban planners, community organizers, municipalities, etc. The precise dynamics of how transformative impact actually comes about are very complex and this topic is beyond the scope of this article. Suffice it to say that transformative change will happen not as a result of a particular SI initiative but through collective action by coalitions of SI advocates, who unite diverse actors, including incumbent actors, and skilfully navigate opportunities for change afforded by changing circumstances. Transformative change is a co-evolutionary, emergent process that involves complex interactions of multiple actors and contextual dynamics [23]. Therefore, transformative capacity is about the ability to influence those co-evolutionary processes whereby transformative impact may become co-produced by many actors, while recognizing that this is very difficult and the degree to which SI actors can exert agency is limited by many contextual factors and structural constraints [12,13,24].

Corresponding with the three institutional dimensions we proposed to assess transformative change, we suggest that also transformative capacity can best be conceptualized in relation to those three dimensions. Therefore, we propose three categories of competences, consisting of the knowledge, 
skills and attitudes that collectives of SI actors need to be able to achieve transformative impact. This categorisation builds on results from the TRANSIT project: the theoretical propositions regarding relations to processes of institutionalisation (see clusters $c$ and $d$ in Appendix A) [1,5], as well as a description of "social learning outcomes that can be assessed in order to evaluate the transformative capacity of social innovation initiatives" [3] (p. 45). Additionally, the notions of "scaling up", "scaling out" [25] and "scaling deep" [26] offer similar conceptualisations, yet we include "scaling up" and scaling "deep" as part of the depth dimension (scaling up referring to the formal/structural and scaling deep to the informal/cultural aspect of institutions).

\subsection{Deepening Competences}

Deepening competences are related to developing and maintaining the transformative characteristics of the institutional changes promoted. This is about the kind of change, i.e., the degree to which the changes promoted involve a transformative kind of change as compared to non-transformative change (i.e., to what extent they challenge, alter and/or replace dominant institutions or reproduce them).

This involves understanding and problematizing, "becoming aware of/critical of/taking distance from/reconsidering/'transcending' institutional configurations in given contexts" [1] (p. 88), that is, the structures, assumptions and values underlying dominant institutions, which bring forth and sustain the problems that SI actors perceive as undesirable [4,27]. For instance, SI actors like Febea, a cooperative promoting ethical banking, need a basic understanding of how the banking system works, what is unethical about it and which forces hold those unethical relations and DOFK in place, in order to create interventions or alternatives that can effectively challenge, alter or replace it [3].

Furthermore, deepening requires identifying and enacting solutions pathways (or theories of change) for practically embedding the aspired changes in informal and formal aspects of institutions: in cultural attitudes, behavioural norms, mental models and discourses, as well as policies, constitutions, organisational structures, success or progress indicators and/or incentive mechanisms. For instance, Ashoka developed a reporting index for assessing the social impact of social enterprises, collaborates with schools and universities to promote social entrepreneurship education and works with governments to advance funding mechanisms for social entrepreneurs.

At the same time, SI actors need to gain clarity about, practically enact and maintain the core values and principles underlying the solutions they wish to promote. These constitute the essence of the social innovative relations and the DOFK promoted by the SI actors. For example, Transition Network developed a list of core values, as well as seven essential ingredients for organising transition town groups. Yet, such core values and principles can also be easily lost when expanding the initiative and interacting with established institutions $[15,28]$. Therefore, it is important to protect those core values or principles along the TSI journey.

Deepening also requires being able to interact strategically \& reflexively with dominant institutions and their formal representatives or decision makers, so as to gain the acceptance, permission, legitimacy, resources or non-interference required to realise their solutions. SI actors will inevitably also re-enact and reproduce some (aspects of) dominant institutions [1,21,27,29]. Hence, they also need to be reflexive or self-aware about the alignment between their values and their practices and how they may unconsciously reproduce or be captured by the dominant institutions that they seek to transform [30] and to develop safeguards against domination and capture by powerful actors [31]. For instance, many ecovillages give ample attention to deeply personal reflection processes to avoid reproducing aspects of individualistic consumer culture or oppressive power relations that they seek to transform [3].

\subsection{Widening Competences}

Widening competences are related to making socially innovative social relations and related DOFK more widely influential and coherent. 
This involves geographically spreading and adapting the practices, models or relational forms to diverse social contexts in terms of the unique cultural, legal, economic, historical, or physical conditions [32]. This may also involve spreading and adapting to different organisational or sectorial contexts. While spreading widely is what is often understood as scaling or diffusing social innovation, in terms of replicating a model in multiple locations, the importance of adaptation to context is often under-emphasized [26].

While spreading can be limited to certain kinds of people who are willing or able to get involved (i.e., sharing similar values, beliefs, status, demographics, etc.), engaging a variety of people is necessary for becoming widely influential instead of remaining a marginal niche phenomenon. This requires tailoring communication and activities to appeal to the perspectives and values and meet the needs of people who may be more sceptical about or even opposed to the SI activities.

Given the proliferation of diverse local context adaptations, experimentation with different ways of doing things in different contexts and the diversity of people getting involved, it is also important to maintain coherence among this diversity [7]. This can involve maintaining boundaries of inclusion and exclusion, and finding a dynamic balance between the two, to protect core values and principles while also not being "too radical or strict" [3] (p. 25).

Widening also involves relating cooperatively with members of the SI initiative as well as other actors in the SI action field [27]. In particular, collaborating effectively with a wide range of initiatives and networks working on related causes can be essential for co-producing a transformative impact. This involves coordinating or aligning a diversity of perspectives, visions, narratives and approaches. Often transformative potential is unrealised due to high fragmentation or dissonance among social innovators working on the same or related causes [1].

\subsection{Lengthening Competences}

Lengthening competences are related to strengthening the persistence and evolutionary self-reproduction of socially innovative social relations and related DOFK over time.

Generating a continuity of resources, activities and essential elements is a vital condition for the persistence of SI [27]. As funding is often scarce for SI activities, SI actors need creative and hybrid resourcing strategies that ensure funding beyond short-term project timeframes. Besides money, the motivation of people to engage in SI initiatives is a key resource, so it is important to maintain high quality motivation to avoid loss of momentum. Also, as people involved in SI initiatives come and go, the continuity of (implicit) knowledge, values, projects and stakeholder relationships is a recurring challenge. This applies to members of SI initiatives as well as founders or important leaders of SI initiatives or networks, where the risk of disintegration can be high when these central figures leave, act ineffectively or die.

Another aspect of lengthening is ensuring resilience in the face of challenges or crises that can involve internal conflicts, loss of resources or challenges by established institutions. This entails negotiating difficult trade-offs during the institutionalisation journey and developing strategies for dealing with the reactions of dominant institutions that attempt to resist, subvert, or capture emerging SI initiatives. Such strategies may include: "complying, irritating, avoiding, resisting, compromising, hijacking, exploiting institutional pressures etc." [33] (p. 21). Confrontations can also emerge from internal differences in values, needs, visions and perspectives or result from misunderstandings or perceived mistakes. Conflicts can lead to significant difficulties, fragmentation or loss of momentum for the efforts of SI actors. Yet, provided with the ability to deal productively with conflict, they can also generate new levels of mutual understanding, empathy or alignment about goals [1].

Lengthening is not just about keeping SI relations and activities the same over time, but also evolving core characteristics by adapting the ways of doing, organising, framing and knowing in response to dynamically changing internal or contextual developments [23], i.e., internal crises, failures or learnings about effective strategies, or external socio-economic policy or environmental changes. 
Finally, lengthening is also about maturing along developmental stages of initiatives, organisations and networks. TSI theory distinguishes four such stages: (1) foundation and orientation, (2) professionalization, (3) waxing and waning and (4) reorganization and adaptation [1] (p. 34). SI initiatives may be at different stages at the same time or go through them repeatedly in different phases and places.

The following section goes on to explain how learning processes can contribute to the development of the above-mentioned competences.

\section{Developing Transformative Capacity through Learning}

TSI theory identifies various mechanisms of gaining transformative capacity, including resourcing, organisational processes, supporting and maintaining motivation of members, or access to institutional actors in politics or the private sector. Their relative importance can vary depending on the type of social innovation and its context. Yet, learning also relates to most of these as a meta-mechanism, in the sense of learning about effective resourcing strategies, how to organise internally, how to interact with institutional actors, and so on. Hence: "reflexivity and social learning are key to the capacity of SI initiatives to contribute to transformative change" [1] (p. 20). This section describes how various types of learning processes take place in social innovation contexts and how these can strengthen transformative capacity.

Learning is a rather multifaceted concept that is understood quite differently by various knowledge traditions [34]. In TSI theory, reflexivity and social learning are defined as "processes of collective experimentation and reflection by which initiatives reach new shared understandings, which in turn become situated in practice" [1] (p. 12). Beyond individual learning, the focus in social innovation contexts is particularly on learning at the collective level through social interaction [1,35-37].

Learning entails the following three aspects: the settings and processes through which learning takes place, learning outcomes that occur as a result of those processes, and the impacts on organisations or wider society, resulting from enacting those learning outcomes [34,38-40]. The impacts of learning in TSI thus involve the deepening, widening and lengthening of institutionalisation processes (Section 3), while the outcomes of learning consist of the changes in knowledge, attitudes and values, skills and relations [41], which encompass "changes in collective meanings and understandings, the reshaping of identities, and new rules and norms of interaction" [1] (p. 50). Together these learning outcomes constitute the transformative competences described in Section 4.

Learning processes that are required for developing transformative competences are described below. These involve various kinds of collective experimentation, interaction and reflection [3,42]. While learning can happen spontaneously, we focus here on intentional learning activities. We describe learning processes in a more generic way, instead of mapping them specifically onto the three types of transformative competences. Also, the prevalence and strength of these learning processes differ significantly per social innovation initiative, so this overview constitutes a generalized representation of recurrent patterns, based on empirics and theory development in the TRANSIT project. Joint, intentional learning takes place in SI initiatives and networks through activities that generate new information or experience, combined with collective reflection on this new information or experience. We consider practicing and experimenting, exchanges, and monitoring and evaluation to be the most relevant activities in SI initiatives and networks in this respect.

\subsection{Practicing and Experimenting}

Perhaps the most prominent way through which social innovators learn is practicing and experimenting with new social relations and ways of doing, organising, framing and knowing. They learn by doing [42-44], through reflecting on their own direct experience of successes and failures in trying to challenge, alter, replace or provide alternatives to dominant institutions. Such experiences lead to a better understanding of dominant institutions, as attempts at changing them can bring forth a direct experience of how these institutions work and what holds the perceived problems in place. 
Through experimentation, envisioning and reflection, they also develop visions and pathways to attain more desirable systems [45]. At the same time, experimentation generates the knowledge and skills needed to build and mature proto-institutions that can challenge, alter, or replace dominant institutions.

An SI initiative spreads more widely as more people start experimenting with adopting and adapting socially innovative solutions to their various local contexts. They may hear about existing SIs through word of mouth; knowledge materials like books, websites or social media; or attending events or activities by SI actors [32]. As a result, they may be inspired to adopt those SI models or practices if they do not already exist in their local context, or otherwise join existing SI actor groups. As they do so, they often learn from engaging with and understanding their local context, while trying out new things that they feel fit their unique context conditions.

\subsection{Exchanges}

SI actors who are already active often seek connections with others doing similar things elsewhere and learn through exchanges among peers. Sharing their challenges, ideas and experiences can help to learn from and build on the failures and successes of others [3]. This can happen locally among SI members of the same group, as well as translocally, among members of other groups in different places [7].

Exchanges with actors in the wider action field, that is, people who are not directly involved or share the same perspectives or practices as particular SI actors, can also be important sources of learning [7]. This may involve learning from other SI actors working on similar or related institutional change ambitions about different approaches. Dialogue as well as confrontation-based interactions can support the capacity to understand and cooperate with a diversity of actors who need to be involved in co-producing the institutionalisation process.

\subsection{Monitoring and Evaluation}

Monitoring and evaluation processes generate learning through data collection and collective reflection about use of resources, performance, organisational culture, theories of change, effectiveness of strategies and achievement of impacts. Some SI actors dedicate ample amounts of time for such processes, recognizing the importance of stepping back from daily activities and making space for these reflections. This can be a source of continuity through boosting motivations and affirmation of core values, as well as a source of new ways of doing, organising, framing and knowing. On the other hand, given their resource-intensive nature, many SI actors also struggle to make time for monitoring and evaluation, which can be a barrier for generating transformative capacity [46].

Monitoring context developments can also be important for understanding societal trends that carry implications or open opportunities for strategic interventions of SI actors [47]. This involves paying close attention to political, socio-economic and cultural trends and forecasts and thereby learning about opportunities for reframing narratives, adapting strategic actions to play into those developments [23].

Additionally, SI actors learn through critical self-reflection [48-50]. Evaluating and reflecting about experiences is vital for producing learning about various aspects of promoting change: not just the effectiveness of strategies, but also implicit assumptions, attitudes and beliefs underlying those strategies [47], as well as the influence of dominant institutions on those efforts. Dominant institutions can be deeply internalised in unconscious thought and behaviour patterns: for instance, by being related to ego-based attachments to power, control, material possessions or status. Hence, attempts at transforming them require not just externally focussed actions but also internally-oriented self-confrontation. Many SI actors recognize the importance of this intimate inner dimension of learning, as "fundamentally related to the ability to take responsibility for others and the world and to step beyond re-enacting patterns of domination and destruction" [3] (p. 86). Therefore, many SI actors consciously set up spaces, tools and organizational practices for supporting collective reflection and self-confrontation processes. This can lead to deep personal and collective transformations. 
Thereby, they promote the awareness about and capacity to change these internalized patterns and to learn to enact more desirable alternatives (e.g., more collaborative forms of communication and decision-making).

The following section goes on to highlight the roles of network leadership for supporting learning processes at different levels.

\section{Roles of Network Leadership for Supporting Learning}

This section focuses on the conditions that networks of social innovation initiatives can create for learning processes to take place, in particular on the roles of network leadership at multiple network levels for shaping the conditions for learning and supporting learning processes.

In the TRANSIT project, networks were found to play three kinds of roles in empowering social innovation actors in developing transformative capacity: funding for local initiatives to set up or run activities; legitimacy as belonging to a recognized brand; and (most prevalent) knowledge sharing, learning and peer-support [1]. The latter role of networks, that is, enabling the learning processes among social innovators, was seen as particularly common, significant and deserving of further research.

A helpful perspective for conceptualizing this role of networks is the notion of "learning networks" developed by Goldstein et al. [51-53]. They empirically analysed learning processes in networks advancing transformative change in education, urban governance, wildfire management and climate adaptation. They defined learning networks as "inter-organizational voluntary collaboratives that nurture professional expertise and describe their potential to catalyse systemic change by disrupting old habits, fostering new relationships, and providing freedom to experiment." [51] (p. 537). Furthermore: "Effective learning networks amplify the potential for transformative change by combining community-based innovation with community-spanning interaction and exchange" [52] (p. 7). They create the spaces for various kinds of learning among actors at different sites and scales, foster a sense of community and shared purpose among network members, and balance local experimentation and autonomy with network-wide coherence to develop collective transformative capacity. Multiple aspects of networks are relevant to be considered in relation to learning process and transformative capacity, including network governance, substructures and network characteristics (e.g., density, centrality, diversity) [54-56]; yet, the aspect of network leadership can be seen as most important [5] and influential in shaping these other aspects [7].

Learning networks require network leadership for effective coordination and engagement. Various terms are used to describe network leaders: "host, servant leader, helper, network weaver and network orchestrator" [21] (p. 11). Goldstein and colleagues [52] defined these network leaders as "netweavers", who "initiate activities that build community by forming relationships, circulating ideas and practices through the network, and promoting a shared identity that provides the foundation for common practice and purpose" (p. 4). Some examples of actors playing different network leadership roles are discussed by Dumitru et al. [3]. Those include inspirational leaders or founders like Rob Hopkins (Transition Towns movement), Calro Petrini (Slow Food movement) and Peru Sasia (European credit union movement). These leaders spread visions and values, collect and share stories of how change can come about, and inspire new followers to join the movement. However, besides such few central leadership figures, members of local initiatives can also play the roles of experts and mentors who support members of other initiatives or "cross-pollinators" [57] (p. 93) who exchange information and practices across local initiatives. Similarly, Risien [7] proposed two categories of actors in learning networks: "curators" who focus on network-wide learning and "sojourners" who focus mostly on improving their practice in their local context.

While certain key individuals are often important, network leadership is usually very different from traditional top-down leadership and involves a more distributed, emergent, collective leadership among various actors at different levels of the network $[3,8,58,59]$. Network leadership may thus be seen as a distributed practice of actors including: members of local SI initiatives (e.g., a Transition 
Town in a particular city), actors in network organizations at national and transnational levels (e.g., Transition Network and its national coordination hubs), as well as meta-networks that foster exchanges and collaborations across networks (e.g., The European network for community-led initiatives on climate change and sustainability (ECOLISE), which includes Transition Network, Global Ecovillage Network, the Permaculture movement and many others) [60].

The following overview outlines the roles of network leadership in strengthening various kinds of learning processes and thereby, the development of transformative capacity. Overall, we suggest two main categories of roles for supporting learning processes and provide some examples for each: (1) shaping conditions and contexts for learning and (2) initiating and supporting activities.

\subsection{Creating Conditions and Contexts}

Hosting spaces for interaction where members of the SI network can connect to exchange experiences, envision desired futures, and reflect on strategic pathways: This is mainly about creating or organising the physical spaces and virtual communication platforms for knowledge exchange and matching specific challenges and answers. This may also involve coordinating with network leaders at different levels to align roles in hosting those spaces for interactions.

Community-building is about setting up and guiding the development of communities of practice [61-63], where a sense of belonging to a community of peers with a shared identity (shared domain, purpose and practice) is an essential motivator to engage in regular exchanges. Risien and Goldstein [53] suggest that building and navigating boundaries of communities of practice are key for developing the transformative capacity of a learning network. Boundaries developed around membership of a network can support professionalization and expertise within their domain, while crossing boundaries can enhance innovation from exchanges with actors in the wider SI action field [51,64], or landscape of practice [63], about diverse perspectives and approaches.

Integrating autonomous experimentation with network learning and cohesion across the network: SI networks tend to promote an experimental culture where local initiatives can act autonomously and try out new approaches [1,51]. This can be a vital source of innovation for the entire network to learn from if local innovations become adopted by others. At the same time, this local autonomy can create challenges and risks when diverging too far from core values or principles endorsed by the network. The role of network leaders can be important to facilitate the spread of local innovations across the network as well as navigating the tension of autonomy and coherence to safeguard the continuity, effectiveness and legitimacy of the network as a whole [52].

Shaping network features that influence the kind and quality of relationships and information flows among network members and other actors: This includes how and by whom the network is governed (e.g., in a decentralized and participatory vs hierarchical and top-down manner) and the substructures of the network (hub and spoke, peer-to-peer, etc.) [54-56]. Network leadership can be influential in monitoring, designing and adapting those network features in ways that respond to the needs of members and enable learning processes that are appropriate for different contexts [7].

\subsection{Initiating and Supporting Activities}

Facilitating workshops and gatherings: SI-actors tend to meet at regional or international network gatherings, but learning exchanges can also consist of smaller sub-groups meeting in person or via online formats. These can be informal exchanges or facilitated workshop settings to learn practice-relevant skills and evaluate their activities. Network leaders can play an important role in organising and facilitating these events and workshops.

Offering direct support as a mentor, coach, advisor: This involves helping people to learn about how to enact the social innovation and DOFK involved and adapt these to local context conditions. This might focus on addressing the concrete challenges initiatives face, offer inspiration for experimenting with new activities and guiding their personal, team or organisational development. 
Creating and disseminating knowledge objects: Many SI networks produce knowledge objects like good practice documents, guidelines, FAQs, literature, videos or wikis. These can support network members to reflect, act more effectively and gain continuity, by drawing on knowledge and tools in the network. Network leaders can have a key role here of aggregating and synthesizing learnings and making the results easily understandable and usable. These knowledge objects often need to be "escorted" by network leaders to make them actually used in practice [1,32]. Knowledge objects like books can also strengthen widening competences by inspiring people to get involved and adding to the knowledge or shaping the discourse in a given action field [3].

Conducting educational activities is a common strategy among many SI networks, not only to support the network members but also for making the knowledge and relations within the network more widely available and impactful. This can take the form of workshops, retreats, consultancy services, learning journeys, or online courses to reach people who are not yet aware or active, so as to inspire and support them to get them involved in the SI activities or learn how to adopt elements in their own contexts. A key challenge for widening is to attract not only like-minded people in these education and outreach activities but to also tailor these to the perspectives of people with different values.

\section{Discussion and Conclusions}

This article presents a conceptual framework that addresses some of the shortcomings and enhances the practical relevance of Transformative Social Innovation theory, as it was produced in the TRANSIT project. Firstly, three dimensions of institutions are articulated: depth, width and length, that allow for a detailed understanding and assessment of transformative impact. Based on these dimensions, three types of competences are defined as constituents of transformative capacity-the collective ability of social innovation actors to turn transformative potential into transformative impact. Next, various types of learning processes are outlined that can contribute to the development of those competences. Finally, the article describes the role of network leadership in strengthening those learning processes. Figure 3 presents an integrated overview of these elements.

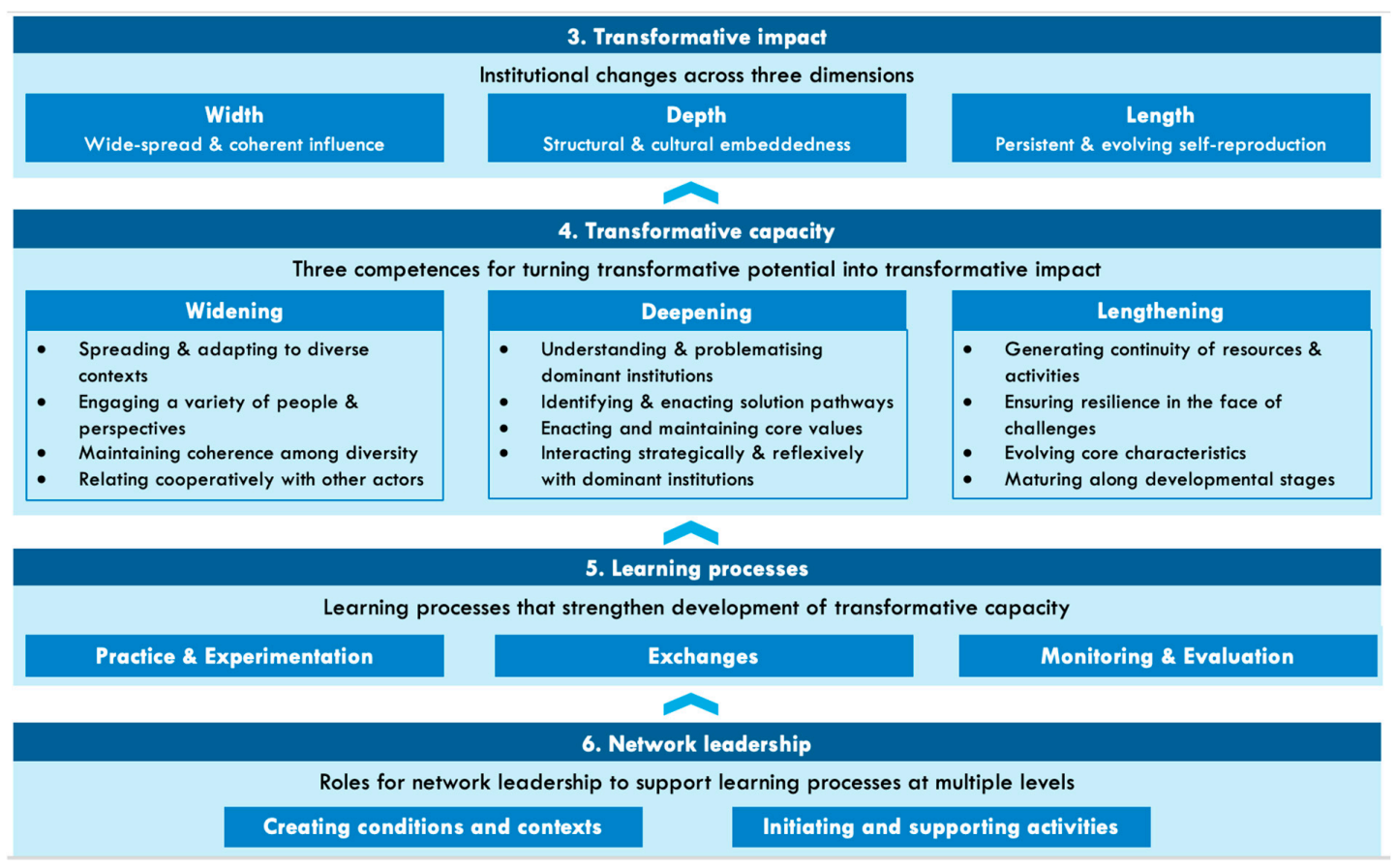

Figure 3. Integrated overview of conceptual framework summarizing the main elements and their components from the respective sections in this article (the numbered titles represent the sections) and the proposed causal direction between them (the light blue arrows between the elements). 
With the conceptual framework presented here, we aim to make the following contributions to the research and practice of social innovation: Firstly, the framework provides a conceptual language for understanding and assessing the transformative impact of social innovations, which is expected to be recognizable and useful in practice. Secondly, it outlines how network leadership can contribute to achieving a transformative impact by supporting learning processes that help to develop transformative capacity. These relationships are only described in rather general terms in current TSI theory, despite the recognized importance of those aspects. Having further developed these aspects conceptually provides a good basis for further empirical research and reflection among practitioners.

We therefore conclude with a research agenda based on the conceptual framework, suggesting relevant research questions and approaches, including tentative propositions that can be tested empirically. By answering these research questions, we hope to make TSI theory more palatable and useful for SI practitioners and to address the need for more practice-relevant outputs of TSI theory [1]. For example, our framework could offer ways of thinking and talking about SI practice that may be useful for SI actors to reflect about and evaluate their transformative change efforts. It could also support SI practitioners in developing empirically grounded theories of change and related monitoring and evaluation tools. These could be used to identify possible gaps between, on the one hand, the learning processes that already take place and the competencies thereby generated, and on the other hand, the competences and learning processes that are needed to realise transformative impact. Clarifying this gap can be supportive for the efforts of SI actors, in particular network leaders, by highlighting possible barriers and suggesting strategies they might employ to strengthen the transformative capacity of their networks.

\subsection{Research Questions:}

The following research questions offer avenues for building on and refining our conceptual framework to further develop TSI theory and increase its practical relevance.

RQ1: To what extent and in which way are the three dimensions of institutional change and the related transformative competences recognizable and useful in practice?

Given the ambition of TSI theory to be relevant in practice, as well as our suggestion that the three dimensions offer a practically useful framing, what value does our framework actually provide to practitioners? Do they offer helpful categories for reflecting about their experiences and strategies, evaluating their efforts and assessing their impacts? These questions can also help to further refine these concepts to reflect more accurately the experiences of SI practitioners.

RQ2: Which relationships can be empirically identified between specific network leadership roles, related learning processes and resulting increases in transformative capacity and impact?

As the elements in our conceptual framework are largely hypothetical at this stage (although derived from empirical observations in the TRANSIT project), identifying such relations in a wider set of empirical cases will make it possible to further develop this framework into a theory of change. In particular, identifying recurrent patterns of relations that can be seen in multiple cases would be important to increase validity and wider relevance. This could also clarify to what extent or which kind of network leadership is important and should be further resourced.

RQ3: Which obstacles commonly prevent or limit network leadership and learning processes from increasing transformative capacity?

Many factors may prevent learning to actually take place (in ways that promote transformative capacity); for instance, a lack of resources and appropriate skills required for effective support and execution of learning activities (e.g., process facilitation, course design, communication skills), focus on 
inappropriate kinds of learning activities, or constraining contexts for learning processes. Identifying whether a limited set of common obstacles exists across a range of empirical cases will be relevant for policy and practice in targeting attempts to remove or overcome such obstacles.

\subsection{Propositions}

The following propositions offer testable hypotheses that can guide further research in answering the above research questions, in particular the second and third.

- In cases of SI initiatives where learning is skilfully cultivated by network leaders, higher degrees of institutionalisation, i.e., transformative impact, will be recognizable as a result.

- Networks where network leadership is not just enacted by a few central individuals but is enacted by various people across network levels are likely to show more diverse and effective learning processes, resulting in higher degrees of transformative capacity and impact.

- Network leadership that skilfully cultivates learning exchanges across networks and actors in the SI field for sustained periods of time will lead to increased transformative capacity through cross-pollination and alignment of efforts, enabling wider influence and deeper embedding.

- Barriers for learning are likely to be higher across networks than within networks, given the differences in values, perspectives and identities. This entails an important challenge for developing widening competence.

- Learning in itself is not enough. As shown, by transition studies, system changes occur as a result of landscape changes and regime pressures and not just the growth of niche innovations. The agency of network leadership will be constrained by important factors beyond their control.

\subsection{Indication of Possible Research Approaches}

Considering the multiplicity of (uncontrollable) factors involved in studying these different factors and relationships, research approaches would need to involve a creative mix of qualitative and quantitative methodologies and experimentation with innovative forms of conducting research.

- Interviews, focus groups and/or participatory workshops with network leaders at various levels of different TSI networks. Comparing the perspectives of members of local SI initiatives and international network organisations about the perceived importance and outcomes of learning processes and the role of network leadership might help to avoid bias.

- The use of Q-methodology [65] might offer a way for prioritising among a range of important learning processes and network leadership roles that have been identified through qualitative methods and combining those results with a quantitative assessment, involving a larger number of cases.

- Embedded action research [66] as part of a (single-/multiple-case) longitudinal study. Studying particular SI initiatives in depth by working with (teams of) network leaders for a longer time would be necessary for tracking developments in transformative competences and impacts resulting from learning processes, which can take a long time to develop.

- Qualitative data analysis of the Critical Turning Point database [67] developed by the TRANSIT project may help to identify patterns across multiple cases of causal relationships between network leadership, learning processes and increases or decreases in transformative capacity and impacts.

- Qualitative comparative analysis using fuzzy sets [68] may be useful as an approach to make inferences from a low number of in-depth case studies.

Author Contributions: T.S.: writing—original draft preparation and revision; J.d.K.: writing—review and editing; R.K.: writing-Textual contributions and supervision.

Funding: This research received no external funding but two of the authors were previously funded through the TRANSIT project.

Conflicts of Interest: The authors declare no conflict of interest. 


\section{Appendix A}

Table A1. Overview of case studies in the TRANSIT project.

\begin{tabular}{lc}
\hline \multicolumn{1}{c}{ Social Innovation Network } & Description \\
\hline 1. Impact Hub (IH) & Global network of co-working spaces for social entrepreneurs \\
\hline $\begin{array}{l}\text { 2. Participatory Democracy Observatory } \\
\text { (OIDP) }\end{array}$ & $\begin{array}{c}\text { Network of communities and municipalities reinventing how public money } \\
\text { is spent and prioritized }\end{array}$ \\
\hline 3. Global Ecovillage Network (GEN) & Network of eco-villages and other intentional communities \\
\hline 4. Ashoka & Network supporting social entrepreneurs \\
\hline 5. Basic Income Earth Network & Connects people committed to basic income and fosters informed discussion \\
\hline 6. RIPESS (solidarity economy) & Network of networks for the promotion of solidarity economy \\
\hline 7. Febea/credit cooperatives & Different types of credit cooperatives \\
\hline 8. Time banks & Networks facilitating reciprocal service exchange \\
\hline 9. Living Labs (ENOLL) & co-creative, human-centric and user-driven research, development and innovation \\
\hline 10. FABLABS & Digital fabrication workshops open to local communities \\
\hline 11. Hackerspaces & User driven digital fabrication workshops \\
\hline 12. INFORSE & International network of sustainable energy NGOs \\
\hline 13. La Via Campesina & Aiming for family farming to promote social justice and dignity \\
\hline 14. Living Knowledge Network & Network of science shops and community-based research entities \\
\hline 15. Seed Exchange Network & Protects biodiversity by defending seed freedom for integrity, \\
\hline 16. Transition Towns & self-organization and diversity \\
\hline 17. Slow Food & Grassroots communities working on 'local resilience' \\
\hline 18. Shareable/sharing Cities & Connecting and empowering urban sharing initiatives aiming for a sharing transformation \\
\hline 19. DESIS (Design for Social Innovation and & Network for design for social innovation and sustainability \\
\hline Sustainability) & Associations that co-work in the production of sustainable inclusive habitat \\
\hline 20. International Cooperative Alliance (ICA) &
\end{tabular}

\section{Appendix B}

\section{(?)}

How do TSI processes lead to transformative change?

How are SI networks, initiatives, and people (dis)empowered?

A TSI process

Legend

TSI ${ }_{\text {Soci }}^{\operatorname{Trat}}$

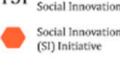

sil nititatives
network

$\mathrm{M}_{\text {Members in SI }}$

3 secomaterial context (b)

Relations in

network formation

Building alliances

Translocal connectivity

Discourse formation

Transposing logics

Transposing logics

(c)

Relations to

\section{rs,}

كم

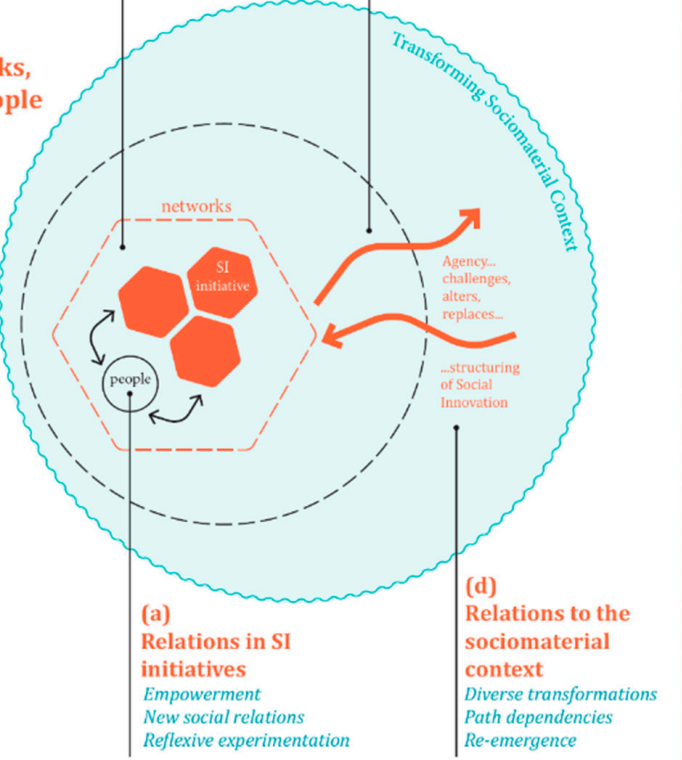

stitutional change

Tr

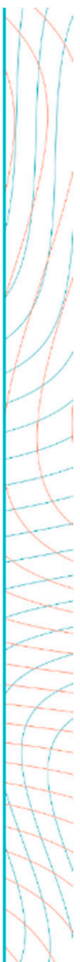

Figure A1. Overview of relations between social innovation and transformative change. 
This figure represents an overview [69] of the dynamic relations between social innovation and the sociomaterial context, which were the focus of the TRANSIT project. The double arrow reflects the reciprocal relationship of TSI with the transforming sociomaterial context. Four levels of social relations in TSI processes are distinguished. These have to do with the collaboration processes and motivations of people within SI initiatives (a), network formation processes (b), institutionalisation processes (c) and the shaping of SI through the broader sociomaterial context (d).

\section{References}

1. Haxeltine, A.; Pel, B.; Dumitru, A.; Kemp, R.; Avelino, F.; Jørgensen, M.S.; Wittmayer, J.; Kunze, I.; Dorland, J.; Bauler, T. TRANSIT WP3 Deliverable D3.4-Consolidated Version of TSI Theory; Deliverable no. D3.4; TRANSIT: Oakland, CA, USA, 2017.

2. Göpel, M. The Great Mindshift. How a New Economic Paradigm and Sustainability Transformations go Hand in Hand, 2nd ed.; Springer: Berlin, Germany, 2016.

3. Dumitru, A.; Lema-Blanco, I.; Mira, R.-C.; Kunze, I.; Strasser, T.; Kemp, R. Social Learning for Transformative Social Innovation; TRANSIT Deliverable 2.3. TRANSIT:EU SSH.2003.3.2-1 Grant Agreement n.613169; TRANSIT: Oakland, CA, USA, 2016.

4. Wolfram, M. Conceptualizing urban transformative capacity: A framework for research and policy. Cities 2015, 51. [CrossRef]

5. Lewis, J.M.; Ricard, L.M.; Klijn, E.H. How innovation drivers, networking and leadership shape public sector innovation capacity. Int. Rev. Adm. Sci. 2017. [CrossRef]

6. Ricard, L.M.; Klijn, E.H.; Lewis, J.M.; Zsa, T. Assessing public leadership styles for innovation: A comparison of Copenhagen, Rotterdam and Barcelona. Public Manag. Rev. 2016. [CrossRef]

7. Risien, J. Curators and sojourners in learning networks: Practices for transformation. Eval. Progr. Plan. 2019, 73, 71-79. [CrossRef] [PubMed]

8. Grin, J.; Hassink, J.; Karadzic, V.; Moors, E. Transformative Leadership and Contextual Change. Sustainability 2018, 10, 2159. [CrossRef]

9. Haxeltine, A.; Pel, B.; Wittmayer, J.; Dumitru, A.; Kemp, R.; Avelino, A. Building a middle-range theory of Transformative Social Innovation: Theoretical pitfalls and methodological responses. Eur. Public Soc. Innov. Rev. 2017, 2, 59-77. [CrossRef]

10. Moulaert, F.; MacCallum, D.; Mehmood, A.; Hamdouch, A. (Eds.) The International Handbook on Social Innovation: Collective Action, Social Learning and Transdisciplinary Research; Edward Elgar Publishing: Cheltenham, UK, 2013.

11. Jørgensen, M.S.; Avelino, F.; Dorland, J.; Rach, S.; Wittmayer, J. Synthesis across Social Innovation Case-Studies; TRANSIT Deliverable 4.4, TRANSIT: EU SSH.2013.3.2-1 Grant agreement no: 613169; TRANSIT: Oakland, CA, USA, 2016.

12. Lowndes, V.; Roberts, M. Why Institutions Matter: The New Institutionalism in Political Science; Palgrave Macmillan: Hampshire, UK, 2013.

13. Cajaiba-Santana, G. Social Innovation: Moving the Field Forward. A Conceptual Framework. Technol. Forecast. Soc. Chang. 2014, 82, 42-51. [CrossRef]

14. Longhurst, N.; Avelino, F.; Wittmayer, J.; Weaver, P.; Dumitru, A.; Hielscher, S.; Cipolla, C.; Afonso, R.; Kunze, I.; Elle, M. Experimenting with Alternative Economies: Four Emergent Counter-Narratives of Urban Economic Development. Curr. Opin. Environ. Sustain. 2016, 22, 69-74. [CrossRef]

15. Bauler, T.; Pel, B.; Backhaus, J. Institutionalization processes in transformative social innovation; capture dynamics in the social solidarity economy and basic income initiatives. In Social Change and the Coming of Post-Consumer Society: Theoretical Advances and Policy Implications; Cohen, M., Brown, H.S., Vergragt, P., Eds.; Taylor \& Francis: Abingdon, UK, 2017; pp. 78-94.

16. Haxeltine, A.; Avelino, F.; Wittmayer, J.M.; Kunze, I.; Longhurst, N.; Dumitru, A.; O'Riordan, T. Conceptualising the role of social innovation in sustainability transformations. In Social Innovation and Sustainable Consumption: Research and Action for Societal Transformation; Backhaus, J., Genus, A., Lorek, S., Vadovics, E., Wittmayer, J.M., Eds.; Routledge: Abingdon, UK, 2018.

17. Avelino, F.; Grin, J.; Pel, B.; Jhagroe, S. The Politics of Sustainability Transitions. J. Environ. Policy Plan. 2016, 18, 557-567. [CrossRef] 
18. Pel, B.; Haxeltine, A.; Avelino, A.; Bauler, T. How can Social Innovation be Transformative? A critical inquiry into imaginaries of reconstructive institutional change. In Proceedings of the Interpretive Policy Analysis Conference, Leicester, UK, 5-7 July 2017.

19. North, P. Ten square miles surrounded by reality? Materialising alternative economies using local currencies. Antipode 2014, 46, 246-265. [CrossRef]

20. Mahoney, J.; Thelen, K. Explaining Institutional Change: Ambiguity, Agency and Power; Cambridge University Press: Cambridge, UK, 2010.

21. Fligstein, N.; McAdam, D. Toward a General Theory of Strategic Action Fields. Sociol. Theory 2011, $29,1-26$. [CrossRef]

22. Lawrence, T.B.; Hardy, C.; Phillips, N. Institutional effects of interorganizational collaboration: The emergence of proto-institutions. Acad. Manag. J. 2002, 45, 281-290.

23. Avelino, F.; Wittmayer, J.M.; Pel, B.; Weaver, P.; Dumitru, A.; Haxeltine, A.; Kemp, R.; Jørgensen, M.S.; Bauler, T.; Ruijsink, S.; et al. Transformative Social Innovation and (Dis)Empowerment. Technol. Forecast. Soc. Chang. 2017. [CrossRef]

24. Beers, P.J.; van Mierlo, B. Reflexivity and Learning in System Innovation Processes. Sociol. Ruralis 2017, 57, 415-436. [CrossRef]

25. Westley, F.R.; Antadze, N.; Riddell, D.; Robinson, K.; Geobey, S. Five configura tions for scaling up social innovation: Case examples of nonprofit organizations from Canada. J. Appl. Behav. Sci. 2014, 50, 234-260. [CrossRef]

26. Moore, M.-L.; Riddell, D.; Vocisano, D. Scaling Out, Scaling Up, Scaling Deep: Strategies of Non-Profits in Advancing Systemic Social Innovation. J. Corp. Citiz. 2015, 2015, 67-84. [CrossRef]

27. Haxeltine, A.; Pel, B.; Dumitru, A.; Avelino, F.; Kemp, R.F.; Bauler, T.; Kunze, I.; Dorland, J.; Wittmayer, J.; Jørgensen, M.S. Towards a TSI Theory: A Relational Framework and 12 Propositions; TRANSIT working paper; TRANSIT: EU SSH.2013.3.2-1 Grant agreement no: 613169; TRANSIT: Oakland, CA, USA, 2017.

28. Mount, P. Growing Local Food: Scale and Local Food Systems Governance. Agric. Hum. Values 2012, 29, 107-121. [CrossRef]

29. Mair, J.; Martí, I.; Ventresca, M.J. Building inclusive markets in rural Bangladesh: How intermediaries work institutional voids. Acad. Manag. J. 2012, 55, 819-850. [CrossRef]

30. Lissandrello, E.; Grin, J. Reflexive Planning as Design and Work: Lessons from the Port of Amsterdam. Plan. Theory Pract. 2011, 12, 223-248. [CrossRef]

31. Voß, J.-P.; Bornemann, B. The Politics of Reflexive Governance: Challenges for Designing Adaptive Management and Transition Management. Ecol. Soc. 2011, 16. [CrossRef]

32. Shawki, N. Understanding the Transnational Diffusion of Social Movements: An Analysis of the U.S. Solidarity Economy Network and Transition US. Hum. Soc. 2013, 37, 131-158. [CrossRef]

33. Wittmayer, J.M.; Kemp, R.; Haxeltine, A.; Avelino, F.; Pel, B.; Ruijsink, S.; Jørgensen, M.S.; Rach, S. Transformative Social Innovation-What Have We Learned in Four Years of Research? TRANSIT Brief 6, TRANSIT: EU SHH.2013.3.2-1 Grant agreement: 613169; TRANSIT: Oakland, CA, USA, 2017.

34. van Mierlo, B.; Beers, P.J. Understanding and Governing Learning in Sustainability Transitions: A Review. Environ. Innov. Soc. Transit. 2018. [CrossRef]

35. Argyris, C.A.; Schön, D. Organizational Learning: A Theory of Action Perspective; Addison Wesley: Reading, MA, USA, 1978.

36. Argyris, C.; Schön, D. Organisational Learning II: Theory, Method and Practice; Addison Wesley: Reading, MA, USA, 1996.

37. Lave, J.; Wenger, E. Situated Learning: Legitimate Peripheral Participation; Cambridge University Press: Cambridge, UK, 1991.

38. de Kraker, J. Social learning for resilience in social-ecological systems. Curr. Opin. Environ. Sustain. 2017, 28, 100-107. [CrossRef]

39. Beers, P.J.; van Mierlo, B.; Hoes, A.-C. Toward an Integrative Perspective on Social Learning in System Innovation Initiatives. Ecol. Soc. 2016, 21. [CrossRef]

40. Cundill, G.; Rodela, R. A Review of Assertions about the Processes and Outcomes of Social Learning in Natural Resource Management. J. Environ. Manag. 2012, 113, 7-14. [CrossRef] [PubMed]

41. Reed, M.S.; Evely, A.C.; Cundill, G.; Fazey, I.; Glass, J.; Laing, A.; Newig, J.; Parrish, B.; Prell, C.; Raymond, C.; et al. What is social learning? Ecol. Soc. 2010, 15, r1. [CrossRef] 
42. Halbe, J. Governance of Transformations towards Sustainable Water, Food and Energy Supply Systems-Facilitating Sustainability Innovations through Multi-Level Learning Processes. Ph.D. Thesis, Universität Osnabrück, Osnabrück, Germany, 2016.

43. Seyfang, G.; Longhurst, N. Desperately seeking niches: Desperately Seeking Niches: Grassroots Innovations and Niche Development in the Community Currency Field. Glob. Environ. Change 2013, 23, 881-891. [CrossRef]

44. Bos, J.J.; Brown, R.R.; Farrelly, M.A. A Design Framework for Creating Social Learning Situations. Glob. Environ. Chang. 2013, 23, 398-412. [CrossRef]

45. Scharmer, C.O. Theory U: Learning from the Future as It Emerges: The Social Technology of Presencing; Berrett-Koehler: San Francisco, CA, USA, 2009.

46. Kemp, R.; Weaver, P.W.; Ruijsink, S.; Wittmayer, J.; Olivotto, V.; Strasser, T. Deliverable 2.5: How to Make Monitoring into a Useful Activity for Social Innovators? Working Paper, Key Insights for Practice and Policy, Lessons for Facilitation Tools and Workshop Report; TRANSIT: EU SHH.2013.3.2-1 Grant agreement no: 613169; TRANSIT: Oakland, CA, USA, 2017.

47. van Mierlo, B.; Regeer, B.; van Amstel, M.; Arkesteijn, M.; Beekman, V.; Bunders, F.G.; de Cock Buning, T.; Elzen, B.; Hoes, A.C.; Leeuwis, C. Reflexive Monitoring in Action: A Guide for Monitoring System Innovation Projects; Communication and Innovation Studies; WUR; Athena Institute: Amsterdam, The Netherlands, 2010.

48. Watkins, K.E. Defining and Creating Organizational Knowledge Performance. Educar 2017, 53, $211-226$. [CrossRef]

49. Mezirow, J. Fostering Critical Reflection in Adulthood: A Guide to Transformative and Emancipatory Learning, 1st ed.; The Jossey-Bass Higher Education Series; Jossey-Bass Publishers: San Francisco, CA, USA, 1990.

50. Mezirow, J. Transformative learning: Theory to practice. New Dir. Adult Cont. Educ. 1997, 74, 5-12. [CrossRef]

51. Goldstein, B.E.; Chase, C.; Frankel-Goldwater, L.; Osborne-Gowey, J.; Risien, J.; Schweizer, S. Transforming with a Soft Touch. Syst. Res. Behav. Sci. 2017, 34, 537-543. [CrossRef]

52. Goldstein, B.E.; Chase, C.; Frankel-Goldwater, L.; Osborne-Gowey, J.; Risien, J.; Schweizer, S. Transformative Learning Networks: Guidelines and Insights for Netweavers, a Report from the Network of Stem Education Centers. 2017. Available online: http://serc.carleton.edu/stemedcenters/index.html (accessed on 6 February 2019).

53. Risien, J.; Goldstein, B.E. Boundaries Crossed and Boundaries Made: The productive tension between learning and influence in transformative networks. 2018; submitted.

54. Lewis, J.M.; Ricard, L.M.; Klijn, E.H.; Figueras, T.Y. Innovation in City Governments: Structures, Networks and Leadership; Routledge: New York, NY, USA, 2017.

55. Kapucu, N.; Hu, Q.; Khosa, S. The state of network research in public administration. Adm. Soc. 2014, 49, 1087-1120. [CrossRef]

56. Keast, R.; Mandell, M.P. Network Performance: A Complex Interplay of Form and Action. Int. Rev. Public Adm. 2013, 18, 27-45. [CrossRef]

57. Kunze, I.; Avelino, F. Social Innovation and the Global Ecovillage Network; TRANSIT Research Report, TRANSIT: EU SSH.2013.32-1 Grant agreement no: 613169; TRANSIT: Oakland, CA, USA, 2015.

58. Popp, J.K.; Milward, H.B.; MacKean, G.; Casebeer, A.; Lindstrom, R. Inter-Organizational Networks: A Review of the Literature to Inform Practice; IBM Center for the Business of Government: Washington, DC, USA, 2014; pp. 93-96.

59. Uhl-Bien, M.; Arena, M. Leadership for organizational adaptability: A theoretical synthesis and integrative framework. Leadersh. Q. 2018, 29, 89-104. [CrossRef]

60. Henfrey, T.W. Designing for resilience: Permaculture as a transdisciplinary methodology in applied resilience research. Ecol. Soc. 2018, 23. [CrossRef]

61. Wenger, E. Communities of Practice: Learning, Meaning, and Identity; Cambridge University Press: Cambridge, UK, 1999.

62. Wenger, E. Communities of Practice and Social Learning Systems. Organization 2000, 7, 225-246. [CrossRef]

63. Wenger-Trayner, E.; Wenger-Trayner, B. Learning in landscapes of practice. In Learning in Landscapes of Practice: Boundaries, Identity, and Knowledgeability in Practice-based Learning; Wenger-Trayner, E., Fenton-O'Creevey, M., Hutchinson, S., Kubiak, C., Wenger-Trayner, B., Eds.; Routeledge: New York, NY, USA, 2015; pp. 13-29. 
64. Jørgensen, U. Mapping and Navigating Transitions-The Multi-Level Perspective Compared with Arenas of Development. Res. Policy 2012, 41, 996-1010. [CrossRef]

65. Shinebourne, P. Using Q method in qualitative research. Int. J. Qual. Methods 2009, 8, 93-97. [CrossRef]

66. Chevalier, J.M.; Buckles, D. Participatory Action Research: Theory and Methods for Engaged Inquiry; Routledge: New York, NY, USA, 2013.

67. Pel, B.; Dumitru, B.; Kemp, R.; Haxeltine, A.; Jørgensen, M.S.; Avelino, F.; Kunze, I.; Dorland, J.; Wittmayer, J.; Bauler, T. Synthesis Report: Meta-analysis of Critical Turning Points in TSI; TRANSIT Deliverable 5.4, TRANSIT: EU SSH.2013.3.2-1 Grant agreement no: 613169; TRANSIT: Oakland, CA, USA, 2017.

68. Ragin, C.C. Qualitative comparative analysis using fuzzy sets (fsQCA). In Configurational Comparative Methods: Qualitative Comparative Analysis (QCA) and Related Techniques; SAGE Publications, Inc.: Thousand Oaks, CA, USA, 2009; Volume 51, pp. 87-121.

69. Transformative Social Innovation Theory (TRANSIT) Project Home Page. Available online: www. transitsocialinnovation.eu (accessed on 26 February 2019).

(C) 2019 by the authors. Licensee MDPI, Basel, Switzerland. This article is an open access article distributed under the terms and conditions of the Creative Commons Attribution (CC BY) license (http:/ / creativecommons.org/licenses/by/4.0/). 